\title{
Permanecer Sus: Contribuindo para a Humanização nos Serviços de Saúde
}

\author{
Torreão, Priscila Alves; Barros, Talia Karen Santos; Teles, Priscyla Santana \\ Ferreira; Martins, Gabriela Flores; Figueredo, Wilton N.; Veras, Renata Meira
}

Universidade Federal da Bahia - pry-alves@hotmail.com

Introdução: o Permanecer SUS consiste em um programa de ensino-aprendizagem proposto pela SESAB cujo objetivo é melhorar o atendimento nas emergências dos hospitais públicos de Salvador através da humanização proposta pela Política Nacional de Humanização (PNH). o programa permite que os estudantes de saúde realizem atividades de acolhimento nas unidades de emergências, maternidades e centros de referências do SUS na cidade de Salvador através de um estágio não obrigatório, tendo como foco principal desenvolver a prática do acolhimento nas unidades, constituindo-se como uma atividade de extensão. Objetivos: o presente trabalho tem como objetivo analisar como o programa Permanecer SUS vem contribuindo para a humanização do atendimento nos serviços de emergências, maternidades e centros de referências que integram o sistema único de saúde na cidade de Salvador/BA. Métodos: Análise com abordagem qualitativa e caráter descritivo com obtenção de dados através de entrevistas semiestruturadas realizadas com um grupo focal de estudantes de saúde que participaram do programa permanecer SUS. Resultados: Pode-se perceber através da analise de entrevistas feitas com estudantes participantes do programa, usuários e profissionais de saúde, que o programa promove através do acolhimento utilizando-se da escuta qualificada, um atendimento mais humanizado aos usuários que procuram esses serviços de saúde. Conclusão: Conclui-se que o programa permanecer SUS pode ser entendido como uma ferramenta de humanização nos serviços de saúde, tanto pelo modo de acolher os usuários, como a transmissão dessas práticas para os profissionais dessas unidades, promovendo assim um atendimento mais humanizado em toda a unidade e não apenas na porta de entrada do serviço de saúde.

Torreão, Priscila Alves; Barros, Talia Karen Santos; Teles, Priscyla Santana Ferreira; Martins, Gabriela Flores; Figueredo, Wilton N.; Veras, Renata Meira. Permanecer Sus: Contribuindo para a Humanização nos Serviços de Saúde. In: Anais do Congresso Internacional de Humanidades \& Humanização em Saúde [= Blucher Medical Proceedings, num.2, vol.1]. São Paulo: Editora Blucher, 2014. ISSN 2357-7282 DOI 10.5151/medpro-cihhs-10803 